\title{
Memoria y ficción: una aproximación al ensayismo de Andreas Kurz a partir de la obra de Robert Musil
}

\section{Memory and fiction: an approach to the essayism of Andreas Kurz's from the work of Robert Musil}

\author{
Mario César Islas Flores \\ Universidad de Guanajuato, México \\ (Estancia postdoctoral) \\ islas_flores@hotmail.com
}

Resumen: En este artículo se intenta ilustrar el vínculo existente entre Viena: otra ficción de Andreas Kurz y el concepto de ensayismo formulado por el también escritor austriaco Robert Musil en textos ensayísticos y también en su novela El hombre sin atributos. Tanto Kurz como Musil consideran que la escritura ensayística conjuga a partes iguales y con idéntico rigor la dimensión autobiográfica y el análisis histórico, la literatura y la historiografía, de ahí que se torne colmado de sentido el intento de establecer una analogía entre ambas escrituras que se inscriben, además, en la añeja y luminosa tradición intelectual austriaca. El fin último de esta aproximación investigativa sería abonar a una reflexión de largo aliento sobre el papel que la memoria juega en la redefinición de los límites intelectuales y éticos de la escritura ensayística.

Palabras clave: biografía, autobiografía, ensayo, memoria, historiografía. 
Abstract: This article analyzes what is the connection between Vienna: another fiction of Andreas Kurz, and the concept of essayism enunciated by the Austrian writer Robert Musil in his essays papers and his novel The Man without Qualities. Both Kurz and Musil consider that in essay writing combine by half and with the same rigor, biographical dimension and historical analysis, literature and historiography, therefore the attempt to establish an analogy between both scriptures that are inscribed becomes full of meaning, in addition, in the aged and luminous Austrian intellectual tradition. The finally purpose from this paper is add to lengthy reflection that exist about role of memory in the redefinition of intellectual and etic limits of essay writing.

Keywords: Biography, Autobiography, Essay, Memory, Historiography.

Recibido: 21 de noviembre de 2018

Aceptado: 15 de diciembre de 2018 https://dx.doi.org/10.15174/rv.vi25.431

A Victor Diaz Arciniega, por su generosidad intelectual y amistad invaluable

\section{Una filosofía evanescente de la historia}

“C Dequeño psicoanálisis vienés" abre Viena: una ficción (Kurz, 2017) con el ímpetu de afirmar a la primera persona del singular, a ese yo que rememora desde una lejanía geográfica, lingüística e histórica (México) una matria (Zwettl) y una ciudad (Viena), a su vez, cercanas y marcadamente distantes entre sí: se trata del adolescente Andreas Kurz que bebe cerveza y lee literatura europea y latinoamericana en un café de su ciudad natal: "Mis lecturas de entonces: Hesse, Joseph Roth, Thomas Mann, García 
Márquez, Vargas Llosa y hasta un Proust muy mal digerido. Mi manera de leer: apolínea al comienzo de la noche, dionisíaca después, desquiciada a su final" (2017: 13).

En otra época, pero igualmente en un café, en el café Theo ubicado en la capital austriaca, Andreas Kurz preparaba su tesis de grado sobre Alejo Carpentier mientras:

\begin{abstract}
disfrutaba la anonimia de una ciudad grande y, a partir de la tercera o cuarta cerveza, contemplaba extasiado la imagen de ese veinteañero que leía en español a un autor muy culto en un ambiente franca y honestamente kitsch, sin pretensiones intelectuales y bastante cercano al submundo vienés: incluso lo frecuentaban prostitutas y ex presidiarios. Es decir: construía una imagen romántica de mí mismo con base en la lectura (2017: 14).
\end{abstract}

La rememoración, más aún, "la fabricación de la historia" (Dosse, 2009: 15-33) es necesariamente a posteriori, por tal motivo, la última línea del párrafo recién citado torna obligado el formular una interrogante: ¿hasta qué punto es verosímil la construcción in situ de la conciencia acerca de la situación en la que el joven Kurz se encontraba en aquel momento? La pregunta es válida de cara a la atribución de significado que todo actor histórico confiere a su realidad presente y es, además, una buena guía para ahondar en las motivaciones y contingencias que usualmente se desvanecen a raíz de la edificación teleológica de los relatos históricos. Esto, en absoluto, lo ignora Kurz, quien en el preámbulo de su libro escribe:

La historia construida de esta manera es falsa; las lecturas, uno de los ingredientes principales, no lo son. Los libros permanecen, aunque se olvide su contenido; moldean y dirigen una existencia. El alcohol se evapora. Su filosofía, sin embargo, forma parte de los libros y de muchos de sus autores (2017: 15). 
La memoria como el alcohol es evanescente, pero algo perdura, algo que la dimensión ficcional permite vislumbrar en la medida que un relato sobre nuestra propia vida sin la criba de la elipsis o la búsqueda del significado mediante la metáfora, por citar dos ejemplos representativos, devendría en una carga insoportable hasta para el lector mejor preparado y dispuesto y es, en virtud de ello, que la sincronía entre vivencia y su inmediata atribución de significado, esa construcción romántica de si mismo consignada por Kurz, se antoja más ficcional que verídica; ficcional como resultado de no poder librar con éxito la encrucijada que la teleología tiende siempre a la memoria.

Empero, lo anterior no significa que esas dos ideas de la felicidad indicadas por Andreas Kurz no posean una efectiva referencialidad biográfica, inclusive, la presencia y vinculación del alcohol con la lectura y la escritura nos aleja, a mi juicio, de la solemnidad a ultranza que algunos autores observan desde la primera línea hasta el punto final de textos en mayor o menor medida autobiográficos, o para decirlo de otro modo: Kurz no busca recubrir cierta desnudez con artilugios retóricos, como no lo hiciera (a juicio de Nina Berberova en sus memorias) August Strindberg (Berberova, 1990: 321).Y esta agudeza con la que el autor analiza la impronta de la realidad pretérita en su vida adulta y la forma en que extrapola esa exigencia, a un tiempo, epistémica y ética a la historia austriaca, es encomiable, como veremos enseguida.

\section{Rememoración y amnesia política}

Uno de los atributos del arco temporal que comprende la transición del siglo xx al xxi es la proliferación de autobiografías ficcionales o pretendidamente históricas bajo un imperativo de signo ideológico y político antes que estético: la restitución del individuo 
frente a los distintos sistemas que disolvieron su presencia en las estructuras y que limitaron su actuar a la directriz de una organización política cimentada, a su vez, en una lógica totalitaria que no admitía distinciones partidistas (Domínguez, 2018; Lefebvre, 1986: 130). En el fondo, Christopher Domínguez y Henri Lefebvre participan de un debate crítico transgeneracional que parte de mediados del siglo xIx y que tiene su simiente en las obras de Carlyle, Emerson y Marx de las que a su vez se desprenden categorías como "grandes hombres", "hombres representativos" o "proletariado" (Carlyle, 1978; Marx, 1998).

Por su parte, en "La biografía como arte neoburgués", texto publicado en el año de 1930, el pensador alemán Siegfried Kracauer historiza sagazmente la reorientación que los estudios biográficos han conocido bajo la hegemonía cultural del capitalismo: políticos y héroes de guerra habían desplazado a los hombres de la cultura. Sin embargo, ahí mismo, Kracauer deja constancia del aspecto que nosotros resaltamos al ubicar, por encima de cualquier otra, la autobiografía de Lev Trotski, es decir, por el compromiso político implícito en tal obra (Kracauer, 2006: 315). Previamente, es pertinente también apuntarlo, los escritores y artistas habían desplazado, a su vez, a los hombres de la iglesia. Andreas Kurz nos dice al respecto:

Cuando la revolución corta las cabezas de Luis xvi y María Antonieta, anula al mismo tiempo el poder espiritual del rito católico. La nación burguesa sustituye a los reyes. Artistas y poetas, intelectuales y estadistas, los grandes hombres como Víctor Hugo y Lamartine retoman los lugares de santos y sacerdotes, las fiestas cívicas y conmemoraciones remplazan la misa religiosa. Los hombres de letras ocupan un lugar privilegiado en esta constelación, un lugar de poder (2013: 10). 
Cabe indicar, por nuestra parte, que la periodización propuesta en este trabajo respecto a la escritura biográfica y autobiográfica estaría cimentada en la restitución de esa autonomía que el poder político había expropiado al individuo; situación advertida por el historiador francés Phillipe Ariés en 1946:

Las generaciones que llegaron a los veinte años alrededor de 1940, o después, dejaron de tener conciencia de la autonomía de su vida privada. No había casi una hora del día que no dependieran de una decisión política o de una agitación pública. Estos niños, estos jóvenes se encontraron de entrada en la historia y no tuvieron que descubrirla; si la ignoraban, era de la manera como se pasan por alto las cosas más cercanas del universo familiar (1988: 35).

Desde el último tercio del siglo pasado en el ámbito de la historiografía francesa empezó a cuestionarse la larga duración propuesta por Fernand Braudel en la que el acontecimiento quedaba desplazado, subsumido en factores de índole estructural (Nora, 1985). En el marco de esa irrupción y justipreciación del yo y de una sensibilidad renovada ante el acontecimiento en la acepción más extensa de la palabra, Viena: una ficción merece ocupar un lugar significativo y no sólo por razones estéticas (una prosa ensayística que aprovecha las cualidades literarias de quien ha escrito La joroba (Kurz, 2016), una novela que es también una rara avis en el horizonte editorial mexicano) sino sobre todo por aquellas que tienen que ver con un combate frontal al falseamiento voluntario e involuntario de la memoria que engendra no sólo "caras risueńas" sino, inclusive, mundos enteros como El mundo de ayer de Stefan Zweig (Kurz, 2017: 87). Sobre el particular, viene al caso citar nuevamente a Kurz, pero en esta ocasión unas líneas de otro de sus textos porque me parece que ellas explicitan a un nivel teórico la crítica recién referida: "El discurso intelectual -abstrac- 
to, multifacético y heterogéneo en sus manifestaciones divergentes- se adjudica la función mimética que - sin exageración- crea ya no realidades específicas y limitadas a entornos individuales, sino mundos enteros" (2010: 127).

Adalbert Stifter y Franz Grillparzer coexisten con Thomas Mann, Elias Canetti, Karl Kraus, Robert Musil, Joseph Roth y Heimito von Doderer en las páginas de Viena: una ficción, pero junto a esas glorias literarias del siglo XIX y Xx de la literatura en lengua alemana, Kurz nos revela a autores prácticamente desconocidos en el contexto literario de habla castellana como Joseph Haslinger y Robert Menasse cuya relevancia es patentizada de forma profusa a lo largo del texto. Y en el mismo sentido, sólo que en el ámbito de la historiografía nos revela la importancia capital del historiador inglés Robert Knight. Esencialmente, a través de esta última tríada de autores, ahondaremos en la dinámica que vincula a la memoria con el olvido, a la autobiografía con la amnesia colectiva y a la historiografía con la ficción.

El segundo capítulo de Viena: una ficción intitulado "El arte del olvido" constituye por sí sólo un penetrante ensayo de historiografía política que ilustra la imprevisibilidad de la historia, o si se prefiere, su previsibilidad en un sentido pragmático y negativo: Kurt Waldheim, esmerado nazi, fue electo presidente de Austria en 1986 a pesar de una protesta que cruzó el Atlántico, o más exactamente: fue electo precisamente como un rechazo a cualquier tentativa injerencista por parte de EUA, por un lado, y de Israel, por otro. En retrospectiva, pasma la capacidad amnésica austriaca, pero pasma también y no en menor medida la propia capacidad de olvido del mundo entero, la cual permitió a Waldheim ser ser el Secretario General de la Organización de las Naciones Unidas durante una década (1971-1981), es decir, que indebidamente ubicó su actuar pretérito en la dinámica de la "prescripción histórica" (Ricoeur, 1999). 
Los trabajos de Robert Knight (Kurz, 2017: 72) son, sin duda, una excelente guía para adentrarnos en ese episodio central en la configuración de la memoria histórica centroeuropea contemporánea en el que resalta la activa participación de Austria en la edificación de una Europa nazista. En aquel contexto electoral, indica Andreas Kurz, sus compatriotas creyeron enfrentarse a una trama conspiracionista urdida contra Austria y reaccionaron votando a Kurt Waldheim que, irónicamente, de no ser por esa amenaza externa habría perdido la elección presidencial, como ya había sucedido tres lustros antes (2017: 60).

Cabe resaltar que, con independencia del limitado poder político que entraña el cargo de presidente en Austria (Kurz, 2017: 59), la victoria de Kurt Waldheim en 1986 tuvo un peso simbólico tremendo, pues implicó una revaloración del pasado nacionalsocialista en la propia patria de Hitler. Por tal motivo, Andreas Kurz afirma que el apellido Waldheim condensa metafóricamente el refinado "arte del olvido austriaco" (2017: 68). Empero, Kurz matiza que en las dos últimas décadas del siglo veinte en el ámbito cultural austriaco, pese a todo, "ya no se permite el olvido tan cómodo de las primeras décadas posbélicas, pero aún es posible negar la responsabilidad por lo acaecido en el pasado individual y colectivo" (2017: 70).

En ese sentido, el atentado contra la norma, sostiene Kurz, vino del exterior: el artículo periodístico “The Waldheim Context: Austria and Nazism" del ya referido Robert Knight generó la inmediata reacción gubernamental austriaca porque en salvaguardar el honor de Kurt Waldheim se jugaba la propia reputación de Austria de cara a su supuesta colaboración con el nacionalsocialismo alemán. Entonces, los historiadores austriacos fueron, incluso, convocados por el ministro de Asuntos Exteriores para que en un simposio se combatiera la difamación de la que era objeto Austria entera (Kurz, 2017: 73). 
Con justeza, Kurz ironiza sobre la ceguera intelectual que llevó al Estado a convocar al gremio de historiadores a pontificar acerca de la inconmovible oposición de Austria al nazismo (2017: 72); no obstante, entiende que no se trata solamente de un movimiento unidireccional, de una directriz que pretende imponerse desde la verticalidad del poder sino que existe también una horizontalidad representada por una cantidad muy significativa de austriacos que convergían con el posicionamiento esencial de su gobierno: ni ellos ni su país tenían responsabilidad alguna en la catástrofe derivada del empoderamiento nazista. Ese ángulo en el que coincidían la élite gobernante y la mayor parte de la sociedad configuraba a "el olvido" como "el a priori de la historia austriaca" (Kurz, 2017: 74). Bajo tal principio, escribe Kurz, "no se trata de memorizar para aprender, sino de olvidar para sentirse libre" (2017: 74).

A partir de lo anterior, debe dimensionarse el colosal esfuerzo que supuso la organización y el trabajo de investigación llevado a cabo a partir de 1998 por un grupo de historiadores austriacos y también de otras naciones, como Robert Knight, para dilucidar el rol de Austria en el contexto del régimen de terror nacionalsocialista. La publicación de los resultados de dicho estudio en 2003 confirmó una sospecha fundada: Austria colaboró solidaria y activamente con el Tercer Reich y además, después de la Segunda Guerra Mundial, fue negligente en el resarcimiento moral y económico a las víctimas (Kurz, 2017: 74). Empero, Kurz indica el peligro contenido en la extensión del informe de la Historikerkommision:

El trabajo de la comisión es notable y noble, pero podría resultar contraproducente: la culpa se transfiere de la mente al papel y el papel convierte el pasado en materia muerta. Quien desee conocer una imagen más o menos auténtica del país durante la era nazi deberá buscar en esas 17 mil páginas, seis veces más volumen 
que la Búsqueda del tiempo perdido, ¿y quién lee de la primera a la última página la gran novela de Proust? (2017: 75).

La ausencia documental es uno de los desafíos más acuciantes en toda tentativa de dotar de sentido a un proceso histórico, pero como bien resalta Andreas Kurz, la monumentalidad de las fuentes también puede devenir en silencio e ininteligibilidad, aunque esto último, me parece, sea siempre preferible a lo primero. Pienso que en el temor justificado de Kurz a la desmemoria derivada (irónicamente) de un enorme reservorio documental se encuentra una de las claves para comprender su concepción de la historia y, por ende, Viena: una ficción. En este sentido, me parece que la siguiente alusión a Kurt Waldheim expresa claramente dicho posicionamiento teórico:

La historiografía fracasa ante la biografía, los documentos -aunque en este caso existan miles de registros burocráticos quisquillosos- no pueden hacer justicia a una vida humana. Mucho menos lo logran los testimonios del involucrado, testigo inseguro y titubeante de su propia existencia (Kurz, 2017: 67).

A la luz de lo anterior, es imperativo el preguntarnos: ¿cómo vencer entonces a la inefabilidad que aparece como ausencia y/o monumentalidad documental? Para encarar este desafío epistemológico me parece especialmente útil remitirme a "Las trampas de la autobiografía”, capítulo tercero del primer volumen de las memorias del escritor húngaro Arthur Koestler, pues en él sostiene que existen dos motivaciones para acometer la tarea autobiográfica: el impulso del cronista y el impulso del Ecce Homo. El primero está pautado por la conciencia de ser protagonista en un determinado proceso histórico y/o por ser el más competente desde el punto de vista intelectual para consignarlo por escrito. La escritura autobio- 
gráfica guiada por el segundo principio parte también de una justipreciación de la experiencia histórica individual, pero la diferencia subyace en el nivel de intimidad que puede revelar al grado de configurar una autobiografía de aliento confesional, sin embargo, ambas perspectivas entrańan un riesgo común:

Evidentemente, el impulso del cronista y el motivo del Ecce Homo se encuentran en los polos opuestos de una misma escala de valores, como la extroversión y la introversión, la percepción y la contemplación. Una buena autobiografía debería ser una síntesis de los dos, lo que pocas veces ocurre. La vanidad de los hombres en su vida pública se resta al valor autobiográfico de sus crónicas; la obsesión del introvertido consigo mismo hace que descuide el paisaje histórico en cuyo centro se mueve (Koestler, 1973: 38).

El francés Philippe Lejeune, sin duda, el mayor estudioso de la escritura autobiográfica destaca, en coincidencia con Koestler, la relevancia de la confesión en toda autobiografía (Lejeune, 1994: 123-148). El ensayismo de Kurz posee un tono bastante confesional; no obstante, considero que en Viena: una ficción termina por imponerse una reflexión analítica sobre el paisaje histórico austriaco, pues el autor intenta ofrecernos un testimonio fiable desde la intimidad de su propia experiencia individual empleando a la literatura como herramienta principal y, de ese modo, a partir de esa (re)apropiación de su realidad pretérita (con todo su componente traumático) revelarnos una panorámica acerca del pasado y la contemporaneidad austriacos, es decir, el yo reivindica su derecho a ser considerado una fuente histórica:

Nací en 1968. Mi memoria individual, que incluye la de mis padres, no alcanza los ańos de la guerra y sólo muy pocos de la posguerra, en cuyo inicio mis padres tenían cuatro años. Sin em- 
bargo, lo que sí alcanza mi memoria es lo suficientemente informativo y significativo como para enterarme del arte del olvido austriaco y del aún no concientizado ni mucho menos superado pasado nazi de mi país. Entonces trato de acordarme. Reafirmo que este intento de recuperar la memoria, en un representante de los nietos de Waldheim, sólo es posible gracias a Waldheim y sus dificultades para acordarse. El arte del olvido austriaco generó la posibilidad de recordar: sospecho que se trata de un efecto colateral no deseado (2017: 76).

A propósito de esto, convendría referir un par de trabajos en los que se problematiza, entre otras cuestiones, la distinción entre autobiografía y autoficción (Casas, 2012; 2014). En nuestro país, merecen destacarse por su aportación teórica y práctica los estudios de Aurelia Valero Pie acerca de la vida y obra del transterrado español José Gaos (Valero, 2012) y de Norma Lojero Vega sobre la escritora tabasqueña Josefina Vicens (Lojero, 2017). Y, por su parte, cabría consignar también que existen dos tradiciones historiográficas que con distintas aproximaciones metodológicas (una más centrada en la oralidad y otra en el análisis textual) se ocupan centralmente de la memoria y la autobiografía, por un lado, considero que la secreta y apresurada recopilación escrita de las anónimas y doloridas voces de los soldados rusos que combatieron en el frente oriental entre 1915 y 1916 durante la Primera Guerra Mundial llevada a cabo por la enfermera Sofía Fedórchenko (2012) funda una perspectiva historiográfica cuya impronta es notable en la obra de la nobel bielorrusa Svetlana Aleksiévich (2016); por otro, en el ámbito literario e inscritos en la misma coyuntura temporal que la obra de Fedórchenko, pero desde el otro frente, es decir, desde Austria-Hungría el ensayista y literato Karl Kraus documentó lingüísticamente los vítores y las lamentaciones tanto de los protagonistas con nombre y apellido como de quienes desde el 
anonimato padecieron la devastación de la entonces llamada Gran Guerra (Kraus, 1991). En los terrenos de Clio, el historiador sueco Peter Englund (2011) ha sido uno de los principales interlocutores de la divisa legada por Sofía Fedórchenko y Karl Kraus.

A partir de la referida reivindicación de Kurz de su condición de testigo y teniendo en mente, además, las tradiciones historiográficas recién consignadas exploraremos la conflictiva relación entre individuo y masa tematizada por la literatura y ensayística austriacas (2017: 35).

\section{Individuo y masa; masa e individuo}

La importancia del estudio Masa y poder de Elias Canetti es bien conocida. El escrutinio irónico al que Robert Menasse somete a esta obra emblemática no lo es en absoluto y al poner esto de relieve, Kurz profundiza sobre la peculiaridad que la dinámica social austriaca impone a la acción individual y con ello enfatiza, una vez más, la propia dimensión autobiográfica de su texto y su vínculo, por supuesto, con la literatura.

En Don Juan de la Mancha, novela publicada en el año de 2007, Menasse narra el nacimiento, formalización y ocaso de una rebelión estudiantil en la Universidad de Viena en los años 70 del siglo pasado. El despotismo de un docente será el motivo de la indignación de tres estudiantes: dos varones y una mujer. La irrupción de este trío en la escena universitaria generará admiración y repudio por igual, pero, al paso de los días, el desgaste mayor lo experimentará el propio grupo hacia el interior debido a situaciones de índole sentimental. La célula anarquista se disolverá de un modo muy particular:

Los tres estábamos sentados y nos mirábamos. Luego dijo Franz: "Solicito, conforme a los estatutos, la autodisolución de nuestra 
célula”. El estudiante que nos acompañaba levantó la mano y dijo: "A favor". Yo me quedé atónito; Franz decía: "Solicitud aceptada por mayoría de votos". [...] Esta historia había comenzado con una broma. Si sólo viene uno, entonces este uno es la masa. Y terminó con que sólo había llegado uno, que proporcionó, él solo, la mayoría de votos. Cada uno es una masa (Kurz, 2017: 27-28).

Este suicidio es, como acertadamente observa Kurz, tragicómico. El verdadero problema surge cuando alguien se resiste a ser armónicamente parte de la masa, cuando un austriaco asume el rol de Karl Kraus, como aquella ocasión en la que el estudiante Andreas decidió no ser uno con la masa en el antiguo campo de concentración nacionalsocialista situado en Mauthausen, y caminó sólo de cara al escarnio y la mofa de sus compañeros escolares:

Se trató de una prueba de valor adolescente. Y definitivamente no la pasé -creo que sólo yo entre unos veinte pubertos-. No entré. Treinta años después, considero esta decisión como el único acto de valor cívico en mi existencia. Sabía que mis compañeros se burlarían de mí. No entré. Y con ese acto de negación puse un hasta aquí a un morbo que vuelve a asesinar las víctimas, que mitifica unos crímenes que de ninguna manera merecen la aureola del mito, que banaliza unos acontecimientos que equivalen a la bancarrota de miles años de cultura humana. Estoy orgulloso de un acto que, tal vez inspirado por la cobardía, me evitó la tentación de la barbarie, y años después me abrió la posibilidad de reflexionar sobre los propios impulsos atávicos y violentos (Kurz, 2017: 77-78).

Es pertinente señalar que este párrafo es radicalmente contrario a una escritura teleológica de la historia cuyos principios epistemológicos y estéticos son, por una parte, la atribución de falsas mo- 
tivaciones y, por otra, la ornamentación retórica (Englund, 2011: 110-113). Que la cobardía devenga en entereza moral y en aliciente para escrudińar no sólo el pasado individual nos aleja de toda construcción romántica de la historia y nos sitúa en un instante de peligro articulado a la manera benjaminiana (Benjamin, 2005: 20), en otras palabras, considero que Andreas Kurz ha sorteado una de las trampas más peligrosas implícitas en toda escritura autobiográfica: la falacia nostálgica (Koestler, 1973: 39). Sin embargo, poco después en Viena: otra ficción nos aguarda otro episodio de la historia personal del autor que de nuevo lo retrotrae al pasado nacionalsocialista, pero éste posee un registro diametralmente distinto, se trata, pues, de un contrapunto:

Yo conté un chiste sobre los judíos masacrados en Auschwitz. Seguro estaba borracho, tenía veinte años y bastantes lecturas en mi cerebro. La inconsciencia adolescente no vale como disculpa, tampoco la ebriedad. Traté de provocar deliberadamente a unos compañeros con ese chiste y busqué la aprobación de otros. Quizá la experiencia traumática de la visita a Mauthausen sirva como disculpa -la necesidad de hundir el trauma-. Con el chiste traté de negar la realidad de lo visto; por unas horas, pude sentirme inocente. El despertar fue horrible y saludable. Durante meses me odié -más de lo que Freud permite-, me sentí basura, experimenté pena de mí mismo. Aún no conocía el famoso sueño que relata Elias Canetti al inicio de sus memorias, pero hoy creo que lo vivía en una variante autodestructiva. No quería salvar mi lengua sino sacrificarla, deshacerme de ese trapo al que no había podido controlar (Kurz, 2017: 80).

Las referencias a Sigmund Freud y a Elias Canetti son comprensibles por razones diferentes, pues, por un lado, se trata del proceso de elaboración del trauma (Lacapra, 2005: 130) y, por 
otro, de la metaforización literaria de dicha experiencia. La toma de conciencia equivale a un remordimiento muy intenso y la tarea de simbolizarlo literariamente deviene en un sincero e inaplazable esfuerzo de expiación. No se trata de superar el crimen a través del olvido sino de marcar su huella de forma perenne en el terreno de la memoria a través de su corporización (la lengua) y de la remisión a uno de los autores más caros a Kurz (Canetti), de este modo, el placer de revisitar la escritura autobiográfica del nobel búlgaro lo confrontará siempre con el capítulo más vergonzante de su propia biografía. Waldheim, por su parte, será siempre un recordatorio metafórico del siempre amenazante y anteriormente referido arte del olvido austriaco.

Acerca de ese entrecruzamiento permanente entre memoria individual y memoria colectiva es pertinente recordar a un autor tan importante como Maurice Hallbawchs, quien fue el primero en historizar dicho nexo (Seydel, 2014; Erll, 2012). El retorno de la memoria como asidero político y paradigma historiográfico después de haber sido desplazada por la "utopía", esto es, por el "futuro" como imperativo bajo la égida del marxismo será un fenómeno que impregne toda la producción historiográfica desde los ańos 80 del siglo pasado hasta las casi dos décadas que ya completa el actual regido por el "momento memorial" (Traverso, 2018: 23-56).

A través de la historia personal de Andreas Kurz hemos apreciado hasta ahora cómo, en un caso, el individuo se resiste a la poderosa corriente representada por la masa y cómo, en otro, sucumbe y cómo, finalmente, una memoria toma cuerpo y es restituida mediante una escritura que, simultáneamente, consigna aciertos y yerros éticos y que no obvia estos últimos porque eso significaría robustecer "el a priori de la historia austriaca", a saber: "el olvido" (2017: 74). Centraremos la mirada ahora enteramente en la forma en que la Masa busca constreñir al máximo y en todo momento decisiones como la observada por Kurz en Mauthausen. Se trata 
ahora, pues, de la omnipresencia de la Sozialpartnerschaft en la vida política austriaca contemporánea. Kurz en alianza intelectual con el ya mencionado literato y ensayista Robert Menasse nos coloca frente a un conglomerado anónimo que encarna un decisivo poder económico y político fáctico que lo inviste como gran elector, legislador y juez supremo de una vida pública francamente ominosa:

Menasse parece creer que lo específicamente austriaco de la Sozialpartnerschaft radica en su falta de visibilidad y, sobre todo, en su ausencia de las instituciones democráticas: no figura en la constitución, no pertenece a partido alguno, no tiene sillón en el Parlamento. Pero opera y durante décadas rigió el quehacer político y económico del país y formó la base de su existencia como Estado (Kurz, 2017: 136).

Intentar darle nombre a lo tácito, a lo inefable, será siempre una labor extraordinariamente compleja y ardua, máxime cuando no pocas veces tanto el destino individual como el de una colectividad dependen de situaciones en absoluto previsibles y que, por tanto, escapan al rango de influencia de acción de los individuos (Islas Flores, 2016). Kurz actualiza las observaciones de Menasse incorporando un nuevo factor de índole política, la inclusión de Austria en la Unión Europea:

Los “cooperadores sociales" serían presidentes, cancilleres, primeros ministros, the happy few privilegiados con miles de millones de euros y puertas abiertas a todas las oficinas de Bruselas, Washington y Moscú; serían quienes pactarían y decidirían al margen de las grandes reuniones internacionales o supranacionales sobre el futuro de cada uno con base en el bienestar o malestar personal del día, la calidad de los alimentos o la generosidad del huésped. ¿Suena a teoría de la conspiración? No lo dudo, pero si analizamos 
nuestros propios modestos entornos laborales, podemos detectar mecanismos parecidos: sinceramente convencidos, decidimos algo que afecta a un puñado de personas, en algún momento de una reunión con amigos, durante una plática familiar, emocionados por un buen día, una buena comida, un nuevo amor; y luego procuramos que esta decisión basada en estados de ánimo irracionales se sancione por algún gremio vagamente democrático, vagamente pluralista y pretendidamente racional (2017: 137-138).

Aquí, Kurz alterna de nuevo los planos microsociales y macrosociales, tal y como lo ha hecho anteriormente con respecto a la rememoración y el olvido. Sus palabras evidencian, la lógica teleológica con la que es revestida la absoluta arbitrariedad con que se toma una decisión trascendente para un individuo o para toda una nación. ¿Cómo el individuo puede escapar a la masa cuando ésta ya se ha instaurado como rasero en la toma de decisiones? Conviene citar aquí a Kurz cuando al comentar la novela Zipper y su padre de Joseph Roth, anota: "muy a la manera de Musil, opone la irracionalidad existencial, el hombre sin atributos, a la engañosa exactitud y previsibilidad de las matemáticas, el hombre con atributos" (Kurz, 2017: 126), es decir, la incertidumbre como divisa para la acción puede librarnos de la acción mecánica, del comportamiento estrictamente gregario.

Empero, la oscilación del ánimo, el encontronazo contra las necesidades de signo variado pone a prueba los principios éticos que orientan una existencia y esto, por supuesto, tiene que ver también con la experiencia intelectual y anímica que se va forjando en el día a día: Kurz negándose a formar parte de la Masa en Mauthausen y, posteriormente, siendo parte de ella en la vileza objetivada como escarnio de la masacre nazista. En la parte final de Viena: una ficción imbricando, nuevamente, presente e historia, el autor intentará responder la interrogante: ¿Cómo evitar ser absorbidos por la 
Masa sin terminar sumidos en la asociabilidad más acérrima? Su reflexión estará ahora guiada bajo el imperativo de dos categorías: ironía y otredad.

\section{La perfecta (in)completitud}

$\mathrm{Al}$ inicio de "El país del casi", tercer y último capítulo de Viena: una ficción, Kurz describe la casi perfecta completitud de Austria y de Viena, su capital, y para ello agrupa elementos tanto del pasado austrohúngaro como de la contemporaneidad de la república austriaca en clave (¿podría ser de otra forma?) irónica:

Austria es el país del casi y Viena su capital. Los Habsburgo casi logran extender su poderío en todo el mundo, Hitler casi lo destruye. En 1900 Viena es casi la ciudad más poblada del planeta y la monarquía casi se hunde. En los Alpes austriacos están las montañas casi más altas de Europa y la Viena de 2015, según varios rankings, es la ciudad que ofrece casi las mejores condiciones de vida de todas, un privilegio que disfrutan incluso los espías del Este y el Oeste porque casi no hay ciudad donde operen más agentes secretos que la capital austriaca. Los esquiadores del país son casi los mejores y dos veces su equipo de futbol casi gana el campeonato mundial. La catedral de San Esteban es casi la iglesia gótica más alta jamás edificada y el castillo de Schönbrunn es casi tan extenso como Versalles... El Heldenplatz vienés (la Plaza de los Héroes) es casi el espacio más urbano abierto más grande de todas las capitales europeas (2017: 113).

Cabe indicar, que desde las primeras páginas de Viena: otra ficción, Kurz consigna esta frecuente y pronunciada oscilación del péndulo histórico austriaco (2017: 15-16). Ambas descripciones, me recuerdan la casi perfecta completud de Kakania, la nación fic- 
cional cuyo referente histórico es el imperio austrohúngaro en $E l$ hombre sin atributos (Musil, 2004: 35-36). Y en Musil como en Kurz, la presencia germana se perfila como esa sombra sempiterna que opaca la luminosidad austriaca, sea por el poderío militar del imperio prusiano durante la época de la Gran Guerra, por el dinamismo cultural de la República de Weimer durante la posguerra,por la aglomeración humana en Berlín, siempre más poblada que Viena, por la imponente catedral gótica de Colonia, pero sobre todo, por ese austriaco que retornara de Alemania para imponer en Austria y en buena parte de Europa un régimen de terror. A propósito de Hiltler y de frente a la actual crisis migratoria que tiene como escenario tristemente privilegiado a Siria, se justifican las siguientes preguntas: ¿existe espacio para quien forzadamente ha tenido que migrar de Medio Oriente a Austria? ¿Y existe lugar para él en el proyecto de la Unión Europea en la que se encuentra inserta la propia nación austriaca?

La solidaridad es excepcional y como siempre, plausible. La nota dominante es, lamentablemente, el rechazo; uno abrumador respecto al árabe o africano que arriban a Europa. La situación recuerda (toda proporción guardada) la exclusión y persecución enfrentada por judíos, gitanos, homosexuales y otros grupos étnicos o religiosos que no encajaban en el modelo de una civilización aria en los días de gloria del nacionalsocialismo alemán. El 15 de marzo de 1938 es, en tal sentido, nos recuerda Kurz, un día glorioso: el día en que el hijo pródigo de la patria austriaca Adolf Hitler retornó triunfante; hecho que mereció el abarrotamiento absoluto de la Heldenplatz, el espacio público más importante de Austria y uno de los más relevantes en el continente europeo (Kurz, 2017: 114). El esquiador Karl Schranz casi lograría igualar esta hazaña en 1972 con motivo de su exclusión de la justa olímpica de invierno que se celebraría ese año en la ciudad japonesa de Sapporo; sin embargo, el elogio de la belleza atlética-para decirlo valiéndome del 
título del profundo y ameno libro escrito por Hans Ulrich Gumbrecht (Gumbrecht, 2006)- no pudo superar el elogio de la belleza nacionalsocialista.

Retomando la oposición fundamental entre sociedades abiertas y cerradas formulada por el pensador vienés Karl Popper (Popper, 2010), Kurz caracteriza al extinto mundo austrohúngaro como una sociedad cerrada que, no obstante (y cómo siempre: irónicamente), permitió el laissez faire. El derrumbe de la monarquía dual desde dicho ángulo de observación estaría caracterizado por una transición interrumpida hacia una sociedad plena y auténticamente abierta en la que el individuo no este subsumido (pese a las apariencias) por un totalitarismo (de rostro afable en comparación de otros, pero no por ello contrario a los principios de una realización cabal del sujeto) político (Kurz, 2017: 95-96).Acerca de este proyecto inconcluso, Kurz señala: "Schnitzler y Zweig evocan mundos perdidos que extrañan y rechazan por igual. Quizá se percaten intuitivamente y en su propia piel -en el caso de Zweig- de la fallida transición entre sociedad cerrada y abierta de la que ellos mismos son víctimas sin la opción de convertirse en verdugos" (Kurz, 2017: 96). En acuerdo con Kurz, sólo me gustaría referir un caso -valiéndome también de un referente literario y que, además, se inserta dentro de la temporalidad austrohúngara- en el que la víctima, Švejk, el personaje central de la obra de Jaroslav Hasek sí deviene en un victimario, así sea indirecto, de quienes a diferencia suya carecen de una gran astucia pragmática (Islas Flores, 2016: 293-294).

Muerta Austria-Hungría, la conversión de la república austriaca en el aliado principal (en el ámbito ideológico, más que en el militar) del nacionalsocialismo hitleriano significó, pues, la consolidación de una sociedad cerrada más radical en términos opresivos que el antiguo totalitarismo de cuño habsbúrgico y/o el austrofascismo de posguerra. Es, por supuesto, el amor a lo propio y el rechazo 
a lo otro, a los otros, a la amenaza externa, lo que explica la aclamación de Hitler, la elección de Kurt Waldheim o el rechazo al inmigrante sirio hoy en día, y ello pese al paradójico cosmopolitismo austriaco: "La constelación multicultural y lingüística", escribe Kurz, "podría explicar una de las raíces del racismo cuasi innato de los austriacos: es auto-odio, un intento desesperado de hallar una identidad donde no puede haber identificación con nada ni con nadie" (2017: 140).

Esa constelación multicultural ha posibilitado también la coexistencia en un mismo espacio de seres tan contrastantes como Karl Kraus y Adolf Hitler. La disyuntiva austriaca formulada por Kurz, precisamente, a partir de los polos extremos de una misma cultura (Kurz, 2017: 29) es un tanto extrema e injusta en términos éticos, en virtud de que no todos pueden disfrutar de una herencia que los exente de cualquier contingencia económica presente y futura y que, por tanto, establezca la base para una crítica frontal e insobornable como en el caso del editor y escritor de la mítica revista Die Fackel (Timms, 1990: 50-51), pero creo entender su sentido: situar la característica ambivalencia austriaca que sólo parece conocer la desmesura y lo antitético: el tiempo parsimonioso del vals y la vertiginosa destrucción-construcción de Viena cristalizada en el vacío ornamentado (Loos, 1972: 43-50); la excelencia literaria y la perversión intencionada de la lengua (Kurz, 2017: 71); el austromarxismo (Bourdet, 1991) y el alcalde antisemita de Viena Karl Lueger sumamente admirado por Hitler; el réquiem inacabable por la sentencia de muerte dictada y ejecutada por los propios austriacos con respecto a su Imperio y la bienvenida al Tercer Reich; el abrazo solidario al migrante y la cálida e inmediata... despedida (Kurz, 2017: 85-86).

La actual solidaridad austriaca respecto a los migrantes se asemeja al ornamento arquitectónico austrohúngaro que guardaba las apariencias, que encubría perfectamente el vacío, léase para el caso, 
la solidaridad franca y genuina. Esta pasión por el ceremonial y las formas que ha devenido en elemento transgeneracional en la cultura austriaca ha dejado su impronta, inclusive, más allá de sus fronteras.

Nostalgia, ambivalencia y ensayismo (a manera de conclusión)

Andreas Kurz ha metamorfoseado su nostalgia en producción textual. Su nostalgia por Austria cuando está en México, su nostalgia por México cuando está en Austria ha devenido en una escritura entrecruzada por dos historias que, por más de un motivo, guardan afinidades, como lo atestigua de forma elocuente un libro coordinado por él y en el que participa, además, con un ensayo sobre Maximiliano de Habsburgo (Kurz, 2015: 37-66). Un Habsburgo en el México decimonónico hubiera resultado per se algo extravagante, pero que el integrante de una de las monarquías más poderosas en la historia de la humanidad haya sido ungido como Emperador de México con el respaldo del ejército galo es, sin duda, lo más desmesurado y extraño que registra nuestra historiografía. En Viena: una ficción, Kurz resalta como el príncipe austriaco viajó a tierras mexicanas con lo más caro a su casa dinástica: "la forma y la etiqueta" (Kurz, 2017: 70), que estarán presentes hasta el desenlace último de este proceso histórico:

En el siglo XIx, México tuvo que presenciar una representación tragicómica de esa veneración de la forma. El 19 de junio de 1867, en el cerro de las campanas queretano, Maximiliano de Habsburgo sólo desea dos cosas: que el pelotón de fusilamiento no apunte a su cara puesto que la etiqueta de la muerte no prevé un cráneo destrozado; y que apunten bien para que muera al instante, ya que 
un Habsburgo retorciéndose en su propia sangre es un espectáculo indigno: hay que ser un cadáver hermoso (2017: 70-71).

En virtud de lo anterior, merece la pena destacar la presencia de México en Viena: una ficción, una presencia más cualitativa más que cuantitativa: la pirámide prehispánica en Cholula utilizada como promontorio para la religión del conquistador hispánico (Kurz, 2017: 24); los múltiples y dolorosos ecos de nuestra Heldenplatz: la Plaza de las Tres Culturas (Kurz, 2017: 117); la seductoramente mala novela Linda 67 (Kurz, 2017: 104-105) y la extraordinaria Noticias del imperio (Kurz, 2017: 71) de Fernando del Paso; no obstante, insisto, la nostalgia de Kurz por México cuando visita Austria, es, creo, la irrupción más importante de nuestra patria en su obra. Y es una suerte de nostalgia también la que surge en mí, como lector, al llegar al final de la obra, pues, a diferencia de la invariable agudeza de Kurz para intuir nexos significativos entre libros, piezas musicales, películas y enrevesados procesos sociohistóricos, su ánimo oscila respecto al poder reivindicador de la escritura a la que considera la "guardiana más eficiente de la memoria" (Kurz, 2017: 81) y por la que "casi es un optimista" como sus admirados Joseph Roth y Thomas Bernhard (Kurz, 2017: 121). Casi. En la última página de Viena nos aguarda un final inesperado, desconcertante, a la luz de quien -atendiendo a la que en sus palabras es la encrucijada insalvable para todo austriaco- ha asumido el rol de combatiente krausiano desde aquella vez que decidió no ser uno con la masa en Mauthausen y caminó sólo de cara al escarnio y la mofa de sus compañeros escolares:

Y yo sigo leyendo literatura austriaca, cada vez con mayor fervor, cada vez más convencido de que no me queda de otra porque es la única ocupación que me permite esperar algo, precisamente porque ella me defiende contra la nefasta influencia de la esperanza, 
porque celebra la derrota, porque vuelve apetecible el apocalipsis, porque "nobel geth die Weltzugrunde", porque Austria es una ficción y su escritura se basa en una ficción y lo que dos veces no existe no me atañe, pues el ensayo es ficción y la ficción es mentira (Kurz, 2017: 157).

Es, pues, la ambivalencia austriaca ineludible, pero no por ello menos inteligente y profunda ¿o quizá precisamente por ello?`Acaso es el yo cómico de Andreas Kurz quien pone punto final a una obra seria, profunda y con un marcado dejo de tristeza? ¿O es su yo caótico quien arroja al piso el puzzle apenas armado por el mero gusto de ver a otro asumir la difícil tarea? ¿O es su yo burlón que casi siente pena del esfuerzo analítico propio y ajeno tan necesario y a la vez tan prescindible? Me he permitido parafrasear libremente una idea que Kurz expone en su ensayo Cratilismo: "El ensayo sí es un género del yo, pero de un yo que no necesariamente es mi yo íntegro. El yo cómico de un yo serio, el yo caótico de un yo ordenado o, al revés, el yo analítico de un yo burlón” (2010: 19).

Como sea, me parece que derivado de todo lo anterior, se justifica una interrogante doble, que atañe, por supuesto, al itinerario intelectual específico del autor, pero que involucra también de un modo más global y genérico al ensayo y a la literatura: ¿hasta qué punto la tensión a la que arriba la escritura ensayística en Viena: una ficción guarda afinidades con La joroba, la opera prima literaria del autor? O expandiendo el foco de nuestros intereses: ¿en qué medida ensayos cuasi literarios como Viena: una ficción se distinguen sustantivamente de la literatura que se está redactando en los días que corren marcada a fuego por la autobiografía y la autoficción?

Coda (o de la poética ensayística) 
Aunque a lo largo de nuestro ensayo hemos intentado establecer claramente qué importancia concedemos al elemento autobiográfico en Viena: una ficción nos gustaría iniciar este apartado final poniendo de nuevo en la palestra una idea vinculada a ese aspecto: "De ahí", apunta Aurelia Valero Pie, "que quien busque conocer a un autor a partir de sus escritos autobiográficos deba tomar en cuenta esa suma de elementos, en la inteligencia de que sus esfuerzos únicamente lo conducirán al proceso expresivo de una identidad narrativa" (Valero, 2012: 13). Los aspectos puntuales del itinerario biográfico de Kurz presentes en su obra de forma esporádica sirvan quizá algún día para que el autor acometa una autobiografía en forma, o bien, para que algún estudioso desarrolle una aproximación biográfica. Por el momento, me gustaría enfatizar en el concepto de identidad narrativa referida por Valero bajo la forma de un acercamiento a los elementos constitutivos que configuran su registro escritural. La presencia de Robert Musil será requerida una vez más en virtud de que, a nuestro juicio, existe cierta coincidencia en ambos autores austriacos en lo concerniente a la articulación de un tipo de escritura ensayística.

Desde sus más tempranos escritos, Musil manifestó su desacuerdo con una visión que separaba razón y sentimiento, en su ensayo intitulado "Lo espiritual, el modernismo y la metafísica", por ejemplo, se pronunció por la búsqueda de un tipo de razón que posibilitara la construcción de una nueva meta para el sentimiento con la finalidad de experimentar una manera distinta de ser hombre (Musil, 1992: 25). Otra ilustración de su postura se encuentra en su aguda y extensa crítica a la teoría cíclica sobre la historia formulada por Oswald Spengler, pues, allí afirma que el hombre está constituido por intelecto y emoción y que negar esto último nos ubicaría en el ámbito de lo inhumano (Musil, 1992: 92). ¿Intelecto y emoción están imbricados también en la escritura de Viena: una ficción? ¿La razón estaría representada por la histo- 
riografía bajo una forma ensayística, mientras que la omnipresente referencia a la literatura encarnaría la dimensión sentimental y anímica? Me parece que esta es la dirección correcta, pero que el itinerario condensado en el libro de Kurz no admite una repuesta tan sencilla. Ahondemos un poco más en la ensayística musiliana antes de intentar formular una hipótesis más compleja al respecto.

Cabe remarcar, que el autor de El hombre sin atributos tuvo claro desde sus inicios como escritor que el intelecto no podía prescindir de la emoción (Musil, 1992: 36). En un breve y elogioso escrito dedicado a su amigo Franz Blei, Musil indicó que el ensayista debía reorientar el pensamiento de los terrenos de la ciencia a los del sentimiento "con la bienaventuranza humana como fin ulterior” (Musil, 1992: 62). Dicho planteamiento, lo colocaba a contracorriente de la casi totalidad de la intelectualidad de habla alemana, para quien la disyuntiva era límpida: optar entre "caballos de potencia” o "potencias del alma” (Kraus, 1990: 117) y bajo ninguna circunstancia buscar la conciliación entre "mecánica" y "alma” (Musil, 1992: 153), es decir, entre pensamiento y emoción.

Musil abogaba, pues, por una racionalidad que reconociera a la emotividad como elemento constitutivo. De ahí también, que considerara al propio ensayo como una combinación de "ética y estética” (Musil, 1992: 342). Inicialmente, apreció en dicho género escritural una superioridad comunicativa con respecto a otros géneros discursivos en la medida que le brindaba la posibilidad, a partir de la rearticulación de ideas y sentimientos, de edificar un nuevo orden cimentado en respuestas tentativas (Musil, 1992: 343). ¿Por qué entonces Musil abandonó esta "forma aforística" de escritura, este "todo compuesto de fragmentos" (Musil, 1992: 201) y se abocó a la escritura literaria? En su inconclusa novela $E l$ hombre sin atributos se nos sugiere una respuesta bajo la forma de una pregunta: "un hombre que desea la verdad llegará a ser sabio; un hombre que se quiere jugar la subjetividad llegará quizá a ser 
escritor; ¿qué debe hacer un hombre que quiere algo intermedio entre ambos?" (Musil, 2004: 261). Esa terra incognita, en la acepción de Siegfried Kracauer (2010: 242), ese espacio a mitad de camino entre la ciencia y el arte que orientara su proyecto escritural encontró su medio de expresión idónea en una escritura en la que podían coexistir pensamiento y emotividad con la venia de la imaginación "porque esas ideas" -escribió el también dramaturgo austriaco- "no son algo puramente intelectual, sino algo intelectual entreverado con lo emocional. Porque puede ser más poderosa la encarnación que la expresión de esas ideas" (Musil, 1992: 305).

Musil arribó, pues, a la literatura desde el ensayo, pero la impronta de dicho género en su obra literaria resulta patente y de primer orden: la escritura fragmentaria, la complejidad del razonamiento, el carácter aproximativo hacia situaciones y personajes son elementos fundantes de su poética. Kurz, parcialmente, ha seguido el mismo itinerario: del género ensayístico transitó hasta los terrenos de la novela y también como Musil, ha llevado con él las preocupaciones y las herramientas estilísticas del ensayista; pienso, a título de ejemplo, en "Interludio I", capítulo de la ya citada novela La joroba en el que Kurz reflexiona acerca de los hábitos de los personajes de ficción cuando no hacen acto de presencia en la obra literaria, es decir, mientras no son convocados al centro de la acción narrativa por el autor (Kurz, 2016: 85-92). No obstante, entre su novela La joroba y Viena: una ficción, en otras palabras, entre su incursión literaria y el retorno a la escritura ensayística el nexo entre pensamiento y emoción se ha reforzado de modo significativo (más sensiblemente que en sus obras precedentes). No podría hablarse (aún) como en Robert Musil de una "escritura imbricada" (Islas Flores, 2015), pero me parece que el derrotero que permite atisbar este último texto es, precisamente, ese. 


\section{Bibliografía}

Aleksiévich, Svetlana, 2016, Últimos testigos. Los niños de la Segunda Guerra Mundial, Ioulia Dobrovolskaia y Zahara García González (trad.), Debate, Barcelona.

Ariés, Phillipe, 1988, El tiempo de la historia, Ramón Alcalde (trad.), Paidós, Buenos Aires.

Benjamin, Walter, 2005, Tesis sobre la historia y otros fragmentos, Bolívar Echeverría (trad.), Contrahistorias, México.

Berberova, Nina, 1990, Nina Berberova. El subrayado es mío, Ana M. Moix (trad.), Circe, Barcelona.

Bourdet, Yvon, 1991, "El austromarxismo", en Nicolás Casullo (comp.), La remoción de lo moderno. Viena del 900, Nueva Visión, Buenos Aires, pp. 135-145.

Carlyle, Thomas y Ralph Waldo Emerson, 1978, De los héroes. Hombres representativos, Jorge Luis Borges (trad.), Cumbre, México.

Casas, Ana (comp.), 2012, La autoficción. Reflexiones teóricas, Arco Libros, Madrid.

(ed.), 2014, El yo fabulado: nuevas aproximaciones críticas a la autoficción, Frankfurt Vervuet, Madrid.

Domínguez Michael, Christopher, 2018, "Un conservador y la izquierda”, Confabulario, 20 de octubre. Disponible en: http:// confabulario.eluniversal.com.mx/roger-scruton/ (consultado: 21/X/18).

Dosse, Francois, 2009, Paul Ricoeur-Michel de Certeau, La historia entre el decir y el hacer, Heber Cardoso (trad.), Nueva Visión, Buenos Aires. 
Englund, Peter, 2011, La belleza y el dolor de la batalla. La Primera Guerra Mundial en 227 fragmentos, Caterina Pascual Söderbaum (trad.), Roca Editorial, Madrid.

Erll, Astrid, 2012, Memoria colectiva y culturas del recuerdo. Estudio introductorio, Johana Córdoba y Tatjana Louis (trad.), Universidad de los Andes, Bogotá.

Fedórchenko, Sofía, 2012, El pueblo en la guerra. Testimonios de soldados en el frente de la Primera Guerra Mundial, Olga Korobenko (trad.), Hermida Editores, Madrid.

Gumbrecht, Hans Ulrich, 2006, Elogio de la belleza atlética, Aldo Mazzucchelli (trad.), Katz Editores, Buenos Aires.

Islas Flores, Mario César, 2015, "La escritura imbricada de Robert Musil: historia, política y mística en El hombre sin atributos", Tesis doctoral, UAM-A, México.

, 2016, "La mirada satírica de Jaroslav Hasek sobre la Primera Guerra Mundial”, en Silvia Pappe y Christian Sperling, Hacia una historiografía de la violencia en México, UAM-A, México, pp. 279-294.

Koestler, Arthur, 1973, Autobiografía. 1. Flecha en el azul, J. R. Wilcock (trad.), Alianza/Emecé, Madrid.

Kracauer, Siegfried, Estética sin territorio, 2006, Vicente Jarque (trad.), Colegio Oficial de Aparejadores y Arquitectos Técnicos de la Región de Murcia/Consejería de Educación y Cultura de la Región de Murcia/Fundación CajaMurcia, Murcia.

, 2010, Historia. Las últimas cosas antes de las últimas, Guadalupe Marando y Agustín D’Ambrosio (trad.), Las cuarenta, Buenos Aires.

Kraus, Karl, Escritos, 1990, José Luis Arántegui (trad.), Visor, Madrid.

, 1991, Últimos días de la humanidad: tragedia en cinco actos, Adan Kovacsics (trad.), Tusquets, Barcelona. 
Kurz, Andreas, 2010, Cratilismo. De la pesadilla mimética en literatura y discurso, Ediciones de Educación y Cultura, México.

, 2013, El general Riva Palacio y la vajilla de Francisco José, Calygramma/Conaculta/INBA, México.

Lacapra, Dominick, 2005, Escribir la historia, escribir el trauma, Teresa Marengo (trad.), Nueva Visión, Buenos Aires.

, 2015, Maximiliano I de México. Ensayos sobre la recepción literaria de un episodio histórico, Ediciones Eón/Universidad de Guanajuato, México.

, 2016, La joroba, Calygramma, México. ,2017, Viena: una ficción, Profética/Cabezaprusia, México.

Lefebvre, Henri, 1986, La violencia y el fin de la historia, Alfredo Llanos (trad.), Editorial Leviatán, Buenos Aires.

Lejeune, Philippe, 1994, El pacto autobiográfico y otros estudios, Ángel G. Loureiro y Ana Torrent (trad.), Megazul-Endymion, Madrid.

Lojero Vega, Norma, 2017, Josefina Vicens. Una vida a contracorriente... Sumamente apasionada, UAM, México.

Loos, Adolf, 1972, Adolf Loos: Ornamento y delito y otros escritos, Lourdes Cirlot (trad.), Gustavo Gili, Barcelona.

Marx, Karl y Friederich Engels, 1998, Manifiesto comunista, Pedro Ribas (trad.), Fundación de Investigaciones Marxistas, Madrid.

Musil, Robert, 1992, Ensayos y conferencias, José Luis Arántegui (trad.), Visor, Madrid.

, 2004, El hombre sin atributos, 2 vols., José M. Saénz, Feliu Formosa y Pedro Madrigal (trad.), Seix Barral, Barcelona.

Nora, Pierre, 1985, "La vuelta del acontecimiento", Le Goff, Jacques y Pierre Nora (eds.), Hacer la historia. Nuevos problemas, Jem Cabanes (trad.), Editorial Laia, pp. 221-239. 
Popper, Karl, 2010, La sociedad abierta y sus enemigos, Eduardo Loedel (trad.), Paidós, Barcelona.

Ricoeur, Paul, 1999, "El olvido en el horizonte de la prescripción”, Paul Ricoeur, et. al., ¿Por qué recordar?, Ediciones Granica, Barcelona.

Seydel, Ute, 2014, "La constitución de la memoria cultural", Acta poética, núm. 35, julio-diciembre, pp. 187-214.

Timms, Edward, 1990, Karl Kraus, satírico apocaliptico. Cultura y catástrofe en la Viena de los Habsburgo, Jesús Pérez Martín (trad.), Visor, Madrid.

Traverso, Enzo, 2018, Melancolía de izquierda. Marxismo, historia y memoria, Horacio Pons (trad.), Fondo de Cultura Económica, Buenos Aires.

Valero Pie, Aurelia, 2012, José Gaos en México: una biografía intelectual, 1938-1969, El Colegio de México, México. 